\title{
CEREBRAL THROMBOPHLEBITIS AND FIBRINOGEN B
}

BY

GILBERT PHILLIPS

(RECEIVED MAY 14, 1948)

Thrombophlebitis of the superficial cerebral veins and the dural venous sinuses is now a well-recognized complication of infective processes, not only about the head and neck but elsewhere in the body (Symonds, 1931, 1937, 1940 ; Purdon Martin and Sheehan, 1941 ; Purdon Martin, 1941). Most observers, however, have realized the difficulty in establishing the final pathological diagnosis, particularly in the early stages where the patient may present with high bilateral papillœdema and no abnormal physical signs, or with some evidence of increased intracranial pressure and paretic or. convulsive phenomena. It is always important in those cases in which visual acuity is deteriorating rapidly as the result of papillœdema to exclude a space-occupying lesion within the skull, as it is not otherwise safe to embark upon a course of repeated spinal drainage in order to save a patient's vision. The diagnostic difficulties are well illustrated in the following case :

\section{Case A}

A boy, aged 6 years, had nothing relevant in the past history. He had suffered from attacks of morning vomiting and anorexia for two months. These had been episodic, the one for which he was admitted to hospital having lasted for four days. The provisional diagnosis was anorexia nervosa or intracranial lesion. On admission, the child was very quiet, thin and wasted. He talked slowly, but there was no dysarthria. There was no history of middle-ear infection or tonsillitis. Full clinical examination did not reveal any significant abnormality, apart from high bilateral papillodema (3 diopters). The ophthalmologist considered that the papillœdema was of recent origin. A radiograph of the skull showed no abnormality. The urine was clear and the Mantoux reaction negative. The blood sedimentation rate was $90 \mathrm{~mm}$. in the first hour, $120 \mathrm{~mm}$. in the second. The cerebrospinal fluid was under greatly increased pressure $(400 \mathrm{~mm}$.). The fluid was clear; there were six lymphocytes per c.mm. ; the total protein was $70 \mathrm{mg}$. per $100 \mathrm{c.cm}$., and the chloride $750 \mathrm{mg}$. per $100 \mathrm{c.cm}$. ; there was no increase in globulin. The fluid was incubated and proved sterile. A blood count showed $4.2 \times 10^{6}$ red blood cells, hæmoglobin $12.5 \mathrm{~g}$., leucocytes 8,500 per c.mm. of blood (neutrophils 55 per cent., lymphocytes 33 per cent., mononuclears 10 per cent., and eosinophils 2 per cent.). In view of the high papillœdema and the episodic vomiting, it was considered that the child might have a tumour in the vermis of the cerebellum, and at that stage the author was asked to see the case in consultation. Previous clinical findings were checked, and it was confirmed that there were no signs of cerebellar dysfunction. The teeth were grossly decayed, with large carious pockets and extensive gingivitis. In view of previous experience with a similar case recorded some time ago (Phillips, 1935), it was suspected that the hydrocephalus might be secondary to cerebral thrombophlebitis due to the oral sepsis, and full dental hygiene was carried out. The carious teeth were extracted and the gingivitis cleared up. Within the following week the papillodema began to subside, and when the child was examined fourteen days later the discs had returned almost to their normal appearance.

In this case, although the diagnosis is based on presumptive evidence, there is little doubt that the oral sepsis was the primary cause of the intracranial lesion which led to the production of increased intracranial pressure.

In view of the work by Cummine and Lyons (1947) in the estimation of fibrinogen $B$ in cases of intravascular thrombosis, it was decided to carry out an estimation of fibrinogen $B$ in the blood in a series of cases of suspected cerebral thrombophlebitis. The purpose of this article is to present the case histories of this series and the conclusions which were drawn from the results of this examination. The following cases have come under the author's care during the past three months.

\section{The Author's Cases}

Case 1.-A woman, aged 22 years, complained of blurred vision for one month. The onset was sudden. She awoke one morning feeling sick and wanted to vomit. Her neck was stiff and vision very blurred. She began to suffer from severe frontal headaches each morning, and the vision became progressively worse. There was nothing significant in her previous history, apart from the fact that since the birth of her last child fifteen months before she had put on 4 stone in weight. There had been no fits. There was no polyuria or polydypsia. Her periods were regular. She had a purulent vaginal discharge. There was nothing relevant in the family history. The patient was an obese young woman, intelligent and co-operative. She could only detect moving objects and was unable to count the number of fingers held before her eyes. Eye movements were full. There was no nystagmus. She had marked bilateral papillœdema ( 2 diopters), The pupils were equal, central, and circular, and reacted to light. Full neurological examination revealed no abnormality, 
apart from diminished abdominal reflexes on the left side. The cardiovascular system was normal. A blood count showed 7;650 white cells per c.mm. of blood (54 per cent. neutrophils and 34.per cent. lymphocytes).

The preliminary impression recorded states: "A review of the history suggests Quincke's syndrome, but there is no history of infection in the teeth, sinuses, or tonsils, although the latter have not been removed." Radiograph of the skull did not reveal any evidence of an intracranial lesion. In view of the papillødema and the transient polyuria, a ventriculogram was performed and the ventricles were found to be small, at the normal depth, and the fluid under greatly increased pressure. A considerable quantity of cerebrospinal fluid escaped from beneath the arachnoid, confirming the presence of an external hydrocephalus. Air studies showed a normal ventricular system. A diagnosis of cerebral thrombophlebitis was then recorded. Lumbar puncture showed a pressure of $420 \mathrm{~mm}$., and repeated spinal drainage was performed, the pressure being reduced half way towards normal on each occasion. The following initial pressures were recorded successively: 500 mm., 270 mm., 190 mm., 230 mm., 190 mm., 165 mm., and $120 \mathrm{~mm}$. Following these spinal drainages, the patient's vision progressively improved and the papillœdema subsided. On discharge from hospital the patient felt perfectly well and her vision had returned to normal.

In this case, no evidence of a focal sepsis could be detected, apart from the fact that the patient had a profuse purulent vaginal discharge, which had been present since the birth of her child twelve months previously.

Case 2.-A woman, aged 25 years, had been quite well until some weeks previously, when she noticed that she had difficulty in lifting the right leg when walking, and the leg became progressively weak. She had shown increasing drowsiness, and complained of a feeling of numbness in the right arm. In the last week she had noticed some blurring of vision, generalized dull headaches, and giddiness. There was nothing relevant in her previous history. No abnormal signs, apart from bilateral papillœdema and a small hæmorrhage in the right disc, were found on examination. She gave a history of repeated sore throats, and radiographs of the nasal sinuses showed dullness in the right antrum. The lung fields were clear radiographically. Lumbar puncture showed clear fluid under a pressure of $220 \mathrm{~mm}$., with four lymphocytes per c.mm. ; the total protein was less than $20 \mathrm{mg}$. per $100 \mathrm{c} . \mathrm{cm}$.. The white cell count was 8,050 per c.mm. with 61 per cent. neutrophils and 35 per cent. lymphocytes. No abnormality was seen in the radiographs of the skull. Ventriculography was decided upon to exclude a space-occupying intracranial lesion. There wàs a considerable quantity of subarachnoid fluid, which escaped when the dura was opened, but the ventricles appeared to be normal in size and depth. Air studies showed a normal ventricular system. A diagnosis of cerebral thrombophlebitis was made, and the patient was treated by repeated lumbar punctures, and was given 10,000 units of heparin by injection. Intracranial pressure gradually subsided to $150 \mathrm{~mm}$., the discs returned almost to normal in the succeeding fortnight, and the vision improved. The patient still complained of some weakness in the right leg on walking any distance.

Case 3.-A man, aged 37 years, was well until four weeks before admission to hospital, when he began to suffer from generalized headaches, which became severe and settled down in the frontal area. Just before admission he had an attack in which his right arm and hand gave a few coarse twitches, and the next thing that he remembers was that he became conscious in hospital. His wife had witnessed the initial fit, and stated that convulsive movements began in the right hand and proceeded up the arm and down the right side to the right leg. He then had a generalized seizure, in which he passed urine and remained unconscious for about half an hour. Two weeks after admission he had a similar fit, and he had three Jacksonian seizures in the right hand in the next fortnight. During this time he complained of blurred vision, which became progressively worse. He said he had had left-sided pleurisy and pneumonia annually for five years previously. He had venous thrombosis in both legs on a number of occasions, and an infected varicose ulcer on the right leg during the past six months. Examination showed well-marked papillœdema of three diopters in both discs, with considerable increase in the blind spots but no contour defect in the visual field. There were no other abnormal neurological signs. There were 11,050 white cells per 8 c.mm. of blood, with 73 per cent. neutrophils, 19 per cent. lymphocytes, and 8 per cent. monocytes. Radiographically the lung fields were clear. There was no evidence of dental sepsis, and no lesion could be detected in the skull. Lumbar puncture revealed a clear fluid under a pressure of $600 \mathrm{~mm}$., with 10 lymphocytes per c.mm., and a protein of $20 \mathrm{mg}$. per $100 \mathrm{c.cm}$. A ventriculogram revealed copious fluid in the subarachnoid space, and the ventricles were normal in size, shape, and position. The second lumbar puncture five days later revealed a pressure of $380 \mathrm{~mm}$., which was reduced by drainage to $160 \mathrm{~mm}$. Repeated lumbar puncture did not produce much reduction of the intracranial pressure, and Mr. Lister Reid performed a left subtemporal decompression, when the brain was found to be under considerably increased tension and bulged out into the decompression opening. The ventricles were again tapped at this operation, and a small quantity of cerebrospinal fluid escaped under considerably increased pressure. At this stage the author was asked to see the case in consultation, and formed the opinion that the patient was suffering from cerebral thrombophlebitis.

Case 4.-A boy, aged 7 years, was well until December, 1947 , when he began to suffer from stiffness in the neck. During the succeeding fortnight he also complained of abdominal pain, and on Jan. 27, 1948, he developed an internal strabismus of the left eye. Examination of the fundi showed a high bilateral papillodema. His temperature was $99 \cdot 4^{\circ} \mathrm{F}$. Lumbar puncture disclosed greatly increased pressure of over $400 \mathrm{~mm}$. ; the cerebro- 
spinal fluid was clear and contained one leucocyte per c.mm. ; chlorides were $720 \mathrm{mg}$. per $100 \mathrm{c.cm}$. and the globulin test negative. The fluid was sterile on culture. A radiograph of the sella turcica did not disclose any abnormality. The boy's general condition remained good until Feb. 5, when his vision began to deteriorate. He was flown to Sydney, and, on admission to hospital here on Feb. 9 he was found to have gross papillœdema with hæmorrhages in each disc. His visual acuity in the right eye was $6 / 36$ and in the left $6 / 24$. There was bilateral sixth nerve palsy, and he had some ataxia in the left hand. Apart from this, there was no abnormal neurological abnormality. There was no evidence of lead intoxication. Radiographs of the long bones were clear. There was no punctate basophilia. The lumbar puncture pressure under Avertin was over $600 \mathrm{~mm}$. A provisional diagnosis of cerebral thrombophlebitis was made, but, in order to exclude a vermis tumour, ventricular estimation was performed. Copious subarachnoid fluid was found, determining a state of external hydrocephalus, and the lateral ventricles, when needled, were found to be small and to contain clear fluid under high pressure.

From Feb. 20 to March 5, this boy had daily lumbar punctures at first, then three times weekly. On each occasion large quantities of clear cerebrospinal fluid were removed, averaging about 20 to $30 \mathrm{c.cm}$. The pressure and papillœdema gradually subsided, and his visual acuity rapidly returned to normal.

Case 5.-A woman, aged 39 years, had complained of frontal headaches for some years, but during the past few months had noticed progressive deterioration of vision and had consulted an ophthalmologist, who detected bilateral papillœdema. Full neurological investigation did not reveal any abnormality, apart from bilateral papillœdema of three diopters. The blood pressure was $160 / 90 \mathrm{~mm}$. Hg. A full blood count was within normal limits. Blood urea was $32 \mathrm{mg}$. per cent. Lumbar puncture pressure was $380 \mathrm{~mm}$., with a protein content of $20 \mathrm{mg}$. per $100 \mathrm{c.cm}$., no cells, and a negative Wassermann reaction. A radiograph of the skull did not reveal any significant abnormality apart from marked hyperostosis diffusa. In appearance the patient was a very short, rather stout female, with fine hair and pale, waxy skin. In order positively to exclude a space-occupying lesion, ventriculography was carried out, and this disclosed an external hydrocephalus with a small ventricular system, which was normal in size, shape, and position. In view of this finding, the diagnosis of cerebral thrombophlebitis was made, although there was no obvious infective focus present. The teeth, tonsils, and sinuses were excluded, and the urinary tract was free from infection. A Graham's test, however, showed no concentration of the drug in the gail bladder, with a faint outline of a large gallstone in the neck. She was given an intravenous injection of $5 \mathrm{c.cm}$. of heparin, which was repeated on two occasions, and at the same time a course of Dicoumarol was begun. Repeated lumbar punctures showed a gradually falling intracranial pressure, which subsided to normal six weeks after admission, at which time she was discharged with normal fundi and free from her headaches. Cholecystectomy has been advised.
Case 6. - A baby boy, aged 15 months, was well until three weeks before admission to hospital on April 22, 1948, when he had a red injected throat accompanied by fever. The child was drowsy and developed a cough, and vomiting occurred several times each day. He lost weight and became dehydrated. On March 11, 1948, he developed left facial paresis, and there was some suspicion of weakness in the extremities of the left side. A course of penicillin, 5 per cent. glucose in saline, was given by intravenous drip. Repeated blood counts did not reveal any significant abnormality, and there was no leucocytosis. Punctate basophilia was not seen. A radiograph of the skull was clear; there was no evidence of lead deposition in the long bones. The fundi were normal but were of the albinotic type. The Mantoux test and the Wassermann reaction were negative. The head circumference was enlarged to twenty inches. The cerebrospinal fluid was said to be under slightly increased pressure : this had not been measured quantitatively. There were 5 cells per c.mm., the chloride was $720 \mathrm{mg}$. per $100 \mathrm{c.cm}$., and there was no increase in protein. At that stage, the present writer, who was then asked to see the case in consultation, suggested a diagnosis of cerebral thrombophlebitis secondary to the follicular tonsillitis.

\section{Discussion}

It is perhaps significant that these cases have a number of factors in common which entitle them to be brought together as a single clinical group and justify the diagnosis of cerebral thrombophlebitis being made on purely clinical grounds without any specific evidence of an actual thrombotic lesion in the dural venous sinuses or their tributary veins These common factors are : a raised intracranial pressure with marked papillœdema; an external hydrocephalus with the accumulation of subarachnoid fluid ; small ventricles normal in size, shape, and position ; a septic focus, usually about the head but in some cases in a remote situation; and a tendency towards spontaneous resolution of the symptoms.

In each of these cases a blood sample was taken and examined for fibrinogen B by Mr. Lyons. As the patients have been referred at different stages in the course of their illness, it was not possible to control the results quantitatively, and no attempt was made in this early enquiry to establish any time relationships between the stage of the illness and the amount of fibrinogen $B$ present. Lyons has pointed out that the fibrinogen $B$ level may rise and fall rapidly during the course of an infective state, and a grade 4 result may fall to grade 1 within a few hours. The significant finding in the investigation, however, was that every case examined returned a positive fibrinogen $B$ result, as shown in the Table. A control series of ten cases of intracranial tumour returned a negative fibrinogen $\mathbf{B}$ in all cases. 
TABLE

SUMMARY OF FINDINGS

\begin{tabular}{|c|c|c|c|c|}
\hline $\begin{array}{l}\text { Case } \\
\text { No. }\end{array}$ & $\begin{array}{l}\text { Clinical } \\
\text { picture }\end{array}$ & $\begin{array}{l}\text { Infective } \\
\text { focus }\end{array}$ & $\begin{array}{c}\text { Fibri- } \\
\text { nogen B } \\
\text { (grade) }\end{array}$ & Result \\
\hline $\mathbf{A}$ & $\begin{array}{c}\text { Vomiting } \\
\text { papillœdema }\end{array}$ & $\begin{array}{l}\text { Dental } \\
\text { sepsis }\end{array}$ & $\begin{array}{l}\text { (Not } \\
\text { tested) }\end{array}$ & Resolution \\
\hline 1 & $\begin{array}{l}\text { Headaches ; } \\
\text { blurred vision ; } \\
\text { papillœdema }\end{array}$ & $\begin{array}{l}\text { Purulent } \\
\text { vaginal } \\
\text { discharge }\end{array}$ & 1 & , \\
\hline 2 & $\begin{array}{l}\text { Right paresis } \\
\text { and } \\
\text { anæsthesia ; } \\
\text { blurred vision ; } \\
\text { headache ; } \\
\text { papillœdema }\end{array}$ & $\begin{array}{c}\text { Tonsillitis ; } \\
\text { antritis }\end{array}$ & 3 & , \\
\hline 3 & $\begin{array}{c}\text { Headaches ; } \\
\text { focal fits ; } \\
\text { blurred vision ; } \\
\text { papillodema }\end{array}$ & $\begin{array}{l}\text { Infected } \\
\text { varicose } \\
\text { ulcer }\end{array}$ & 4 & , \\
\hline 4 & $\begin{array}{l}\text { Diplopia ; } \\
\text { papilloedema ; } \\
\text { blurred vision }\end{array}$ & $\begin{array}{c}\text { Not } \\
\text { detected }\end{array}$ & 1 & , \\
\hline 5 & $\begin{array}{l}\text { Headaches ; } \\
\text { blurred vision ; } \\
\text { papillœedema }\end{array}$ & $\begin{array}{c}\text { Chole- } \\
\text { cystitis } \\
(\text { ?empyæma) }\end{array}$ & 3 & , \\
\hline 6 & $\begin{array}{l}\text { Vomiting ; } \\
\text { enlarged head }\end{array}$ & Tonsillitis & 3 & Pending \\
\hline
\end{tabular}

The method of carrying out the examination for fibrinogen $B$ is simple, and has been described by Cummine and Lyons (1947): "The reagent for the fibrinogen B test is prepared as follows. Two grammes of beta naphthol are-dissolved in 100 millilitres of 50 per cent. alcohol and the solution is exposed to oxygen when it turns brown. It is not essential to aerate the reagent, but when this is done it appears to increase the rate of gel formation. One millilitre of plasma is added to 0.25 millilitre of this reagent in a $15 \times 100$ millimetre tube, mixed immediately, and allowed to stand for ten minutes. At the end of this period the plasma is examined for clot formation. The presence of a clot indicates that fibrinogen B is present in the plasma." The degree of the reaction is graded from 1 to 4 depending on the physical characters and intensity of the resultant clot.

Further enquiry must be directed towards the relation between the intensity of the fibrinogen $B$ reaction and the particular stage of the thrombotic lesion, and a large series of suspected cases must be studied before the positive diagnostic merit of this test can be accepted. Cummine and Lyons have shown that circulating fibrinogen $B$ produces rouleaux formation of red blood cells, and that by increasing platelet fragility it may liberate thrombo- plastin into the blood stream. Under suitable conditions of low pressure and slow rate of flow, this mechanism predisposes to intravenous thrombosis. Symonds (1937) has, moreover, pointed out the probable role of bacteræmia which may add a further predisposition through mural damage in the venous sinus or its tributary veins

If a thrombotic lesion in relation to the arachnoid granulation filters is accepted as the pathological basis for this condition, there should be little hesitation in deciding that surgical decompression will be of little help in reducing the intracranial pressure. It has been shown in the number of cases presented here that the characteristic finding is a large lake of subarachnoid fluit which is, no doubt, dammed back by the blockage of the reabsorbing mechanism. It is likely, therefore, that subtemporal decompression, which, in the presence of a spaceoccupying lesion, may prove effective by removing venous stasis as the result of the extra room provided, will not be effective here, where a portion of the venous system is partly or totally filled by clot and reabsorption of cerebrospinal fluid is prevented. The therapeutic attack should be directed, as soon as one has excluded a space-occupying lesion, towards removal of the infective focus, to inactivation of the circulating prothrombin in the blood by intravenous injection of heparin, to the reduction of prothrombin formation in the liver with Dicoumarol, and to decompressing the optic nerves in the case of rapidly deteriorating vision by repeated spinal drainages. The use of anti-coagulants must, of course, be controlled by a regular examination of the patient's prothrombin time, coagulation time, and fibrinogen B level.

At the present time further studies are being directed to the prothrombin and coagulation times and the fibrinogen B levels, in a series of similar cases throughout the course of the illness.

\section{Summary}

Seven cases of cerebral thrombophlebitis are described. In all six cases examined the blood revealed the presence of fibrinogen $\mathbf{B}$.

\section{REFERENCES}

Cummine, Harold, and Lyons, Raymond (1947). Proc. Urol. Soc., 1, 17. (1948). Brit. J. Surg. (In the press.)

Martin, J. Purdon, and Sheehan, H. L. (1941). Brit. med. J., 1, 349.

(1941). Ibid., 1, 537.

Phillips, Gilbert (1935). Med. J. Aust., 2, 289.

Symonds, C. P. (1931). Brain, 54, 55.

(1937). Ibid, 60, 531.

(1940). Brit. med.' J., 2, 348. 